УДК 631.452:504.54:631.582

ОСОБЕННОСТИ ФОРМИРОВАНИЯ ЭФФЕКТИВНОГО ПЛОДОРОДИЯ ПОЧВ ПОД РАСТИТЕЛЬНЫМИ ЦЕНОЗАМИ АГРОЛАНДШАФТА

\author{
Медведев И.Ф., Бузуева А.С., Губарев Д.И., Верин А.Ю. \\ ФГБНУ «Научно-исследовательский институт сельского хозяйства Юго-Востока», \\ e-mail: squirel-rush@mail.ru
}

\begin{abstract}
С учетом гидротермического коэффициента вегетационного периода были выделены 3 погодных типа засушливый $(\Gamma T К=0,4)$, увлажненный $(\Gamma T К=1,1)$ и влажный $(\Gamma T К=1,4)$. В условиях сильной засухи запас почвенной влаги был ниже на $61 \%$ относительно условий повышенной влагообеспеченности. С повышением уровня запасов влаги в почве отмечается лучшее использование нитратного азота. Распределение влаги и элементов питания по фазам вегетации яровой пшеницы было равномерным, с постепенным уменьшением от фазы кущения к фазе полной спелости. Выявлена особенность формирования элементов питания в зависимости от вида использования земли. На залежных землях содержание нитратного азота в среднем по профилю на $35 \%$ меньше, чем на зернопаровом, и на 51 \% меньше, чем на зернотравяном севооборотах. Целинные земли оказались еще менее обогащены нитратным азотом, чем залежные. Значительная часть фосфора по всем видам использования земли сосредоточена в слое $0-40$ см - 23,2\%. В среднем в метровом слое почвы содержание доступного фосфора под залежью было в 3,5 раза выше, чем под остальными видами использования пашни. Установлена зависимость уровня продуктивности от способа использования почвы. В среднем по всем годам исследования максимальным (2,28 т з.ед./га) он был на залежи, минимальным на целинных участках (1,5 т з.ед./га). Продуктивность пашни занимала промежуточное положение между соответствующими показателями целины и залежи (1,85 т з.ед/га). Растения на зернотравяном севообороте, из-за более высокого уровня плодородия почвы, всегда развиваются лучше, чем на зернопаровом севообороте, что сказывается на степени усвоения питательных элементов для формирования продуктивности.
\end{abstract}

Ключевые слова: яровая мягкая пшеница, агроландшафт, целина, залежь, продуктивность, нитратный азот, подвижные формы фосфора

\title{
FEATURES OF FORMATION OF EFFECTIVE FERTILITY OF SOILS UNDER BROWNING AGROLANDSCAPE
}

\author{
Medvedev I.F., Buzueva A.S., Gubarev D.I., Verin A.Yu. \\ Agricultural Research Institute of South-East Region, Saratov, e-mail: squirel-rush@mail.ru
}

Taking into account the hydrothermal coefficient of the vegetative period, 3 weather types were formed - arid $(\mathrm{GTK}=0.4)$, moist $(\mathrm{GTK}=1.1)$ and wet $(\mathrm{GTK}=1.4)$. In conditions of severe drought, the soil moisture reserve was lower by $61 \%$ relative to conditions of high moisture availability. With the increase in the level of moisture reserves in the soil, the best use of nitrate nitrogen is noted. Distribution of moisture and nutrients in the phases of vegetative growth of spring wheat was uniform, with a gradual decrease from the phase of tillering to the phase of full ripeness. The peculiarity of the formation of food elements is revealed depending on the type of land use. In the fallow lands, the content of nitrous nitrogen is $35 \%$ less on average in the profile than in the sulphurous and $51 \%$ less than in the grain-crop rotations. The virgin lands were even less enriched with nitrate nitrogen than the fallow. A significant part of phosphorus for all types of land use is concentrated in the $0-40 \mathrm{~cm}$ layer $-23.2 \%$. On average, in the meter layer of soil, the content of available phosphorus under the deposit was 3.5 times higher than under the other uses of arable land. The dependence of the level of productivity on the way soil is used is established. On average, for all years of the study, the maximum $(2.28 \mathrm{tgr.un} / \mathrm{ha})$ he was on the deposit, the minimum on the virgin lands (1.5 $\mathrm{tgr.un} / \mathrm{ha})$. The productivity of arable land occupied an intermediate position between the corresponding indices of the virgin land and the reservoir (1.85 t gr.un/ha). Plants on grain-crop rotation, because of a higher level of soil fertility, always develop better than on a grain-steamed crop rotation, which affects the degree of assimilation of nutrients for the formation of productivity.

Keywords: spring soft wheat, agrolandscape, virgin land, reservoir, productivity, nitrate nitrogen, mobile forms of phosphorus

Интенсивное длительное использование земель сельскохозяйственного назначения и активность эрозионных процессов в агроландшафте привели к заметным потерям плодородия. Восстановление таких почв - процесс очень длительный. Один из основных приемов восстановления плодородия деградированных почв - перевод пашни из интенсивного использования в залежное состояние.

Ежегодное поступление отмирающей органики в почву формирующейся под естественным травостоем залежной паш- ни постепенно восстанавливает уровень ее плодородия [1].

Индикаторами состояния почвы по уровню плодородия, наряду с уровнем ежегодной урожайности биомассы, являются содержание в почве минерального азота, подвижные формы фосфора $[1,2]$.

Цель исследования: изучить динамику формирования элементов эффективного плодородия под различными растительными ценозами агроландшафта, продуктивность полевых ценозов на примере яровой пшеницы 
в условиях зернопарового и зернотравяного севооборотов и экстенсивно используемой в агроландшафте залежи и целины в зависимости от погодных условий и применяемых удобрений.

\section{Материалы и методы исследования}

Исследования проводились на полях ФГБНУ «НИИСХ Юго-Востока» на черноземе южном малогумусном маломощном глинистом. Яровая пшеница возделывалась в двух 6-польных севооборотах: зернопаровой (пар, озимая пшеница, яровая пшеница, просо, 2 года яровая пшеница) и зернотравяной (3 года многолетние травы, 3 года яровая пшеница). Для сравнения использовались залежный ценоз с возрастом 35 лет и целина. Делянки с удобрениями располагались в один ярус. В первом повторении размещение делянок последовательное, в последующих повторениях - рендомизированное. Учетная площадь одной делянки составляет $100 \mathrm{~m}^{2}$. Схема опыта включала в себя 3 варианта в 3-кратной повторности. Исследования проводились в полевых условиях по фенологическим фазам яровой пшеницы (кущение, колошение, полная спелость), залежного и целинного ценозов - в фазу массового цветения. По слоям через 10 см до 1 м проводилось определение содержания подвижной формы фосфора (в 1\%-ной углеаммонийной вытяжке по Мачигину ГОСТ 2625-91), минерального азота (по ГОСТ 26423-85). Продуктивность растительного ценоза определяли методом укосов с пересчетом на абсолютно сухую массу (16\%), зерна - учетом биологической урожайности на корню с пересчетом на влажность $14 \%$. Сорт яровой мягкой пшеницы «Воевода», технология возделывания - общепринятая.

\section{Результаты исследования и их обсуждение}

Изучаемый агроландшафт представлен основными элементами растительной структуры, интенсивно использованной под полевые севообороты пашней, залежью и целиной. Активность процессов формирования почвенного плодородия в агроландшафте определяется прежде всего долей интенсивно использованной в агроландшафте пашни. Залежь и целина играют роль восстановителей почвенного плодородия. Наряду с пополнением органического вещества основная роль фитоценозов в агроландшафте - это борьба с эрозией и деградацией почвы [3].
При длительном возделывании яровой пшеницы в севообороте важную роль в формировании ее урожайности играют почвенно-экологические условия и прежде всего уровень обеспеченности и соотношения между основными элементами почвенного плодородия, запас влаги в почве $[4,5]$.

В ходе исследований проведен анализ процессов формирования потенциального плодородия основных растительных систем в агроландшафте. С учетом гидротермического коэффициента (ГТК) вегетационного периода были выделены 3 погодных типа - засушливый (2012 г.), увлажненный (2013 г.) и влажный (2017 г.). В засушливом году ГТК за период вегетации яровой пшеницы составил 0,4, что по классификации означает «сильная засуха». В этот год после окончания снеготаяния суммарный запас продуктивной влаги метрового слоя почвы под пшеницей достиг 207,7 мм, но в условиях острой засухи за один месяц (с апреля по май) уменьшился на $42 \%$, а в пахотном слое (0-30 см) - на 75,2\%. В фазу кущения яровой пшеницы запас продуктивной влаги метрового слоя уменьшился в 2 раза (до 104 мм). Минимальное содержание влаги находилось в слое 0-40 см. К фазе колошения яровой пшеницы запасы продуктивной влаги метрового слоя почвы по сравнению с предыдущей фазой уменьшились на $39 \%$. Наиболее активно продуктивная влага использовалась из слоя почвы 60-100 см. За время между фазами колошения и полной спелости отмечалось повторное обострение засухи. К фазе полной спелости запас продуктивной влаги уменьшился по сравнению с фазой колошения на 7,3\%.

Растениям для своего развития, наряду с влагой, требуется комплекс питательных элементов.

В питании растений большую роль играют подвижные и легкоусвояемые формы азота, количество которых в почве очень перманентно.

В фазу кущения яровой пшеницы в почвенном слое 0-50 см нитратного азота содержалось 7,1 мг/кг. Концентрация азота происходила в верхнем (0-10 см) слое почвы. Колошение отмечается снижением содержания нитратного азота, по сравнению с фазой кущения на 20,5\%. По окончании колошения азот уже почти не усваивался из почвы, что, возможно, связано с процессом реутилизации азота самим растением.

Доступный для питания растений фосфор находится в почве в форме легкорастворимых фосфатов. В фазу кущения яровой 
пшеницы содержание подвижного фосфора составило 19,2 мг/кг. Период колошения характеризуется снижением содержания фосфора на 24\%, что объясняется максимальным расходованием его на формирование вегетативной массы. В фазу спелости отмечается увеличение содержания фосфора в почве до 19,2 мг/кг за счет низкого использования его растениями.

Вегетативная масса растений на момент кущения составила 0,29 т/га. С увеличением в фазу колошения на 70,4\% и в фазу спелости еще на $61 \%$, что составило 0,80 т/га. Отмечена высокая отрицательная корреляционная зависимость массы растений с содержанием нитратного азота в почве $(\mathrm{r}=-0,86)$, а с содержанием подвижного фосфора - низкая $(\mathrm{r}=0,23)$.

В увлажненный тип погоды $(\Gamma \mathrm{TK}=1,1)$ запас продуктивной влаги в фазу кущения составил 167,5 мм. Иссушения пахотного горизонта не происходило. Минимальное содержание влаги отмечалось на глубине 50-70 см. Период фазы колошения характеризовался экстремально влажными погодными условиями с суммой осадков 239,5 мм. Запасы влаги метрового слоя увеличились на 43 \%. За время между фазами колошения и полной спелости отмечалась слабая засуха $(\Gamma \mathrm{TK}=0,6)$, но выпавшие в предшествующий период осадки позволяли растениям развиваться в нормальном режиме. Запас продуктивной влаги уменьшился по сравнению с фазой колошения на $56 \%$.

Состояние минерального азота в почве находится под влиянием погодных условий [4]. Распределение азота по фазам вегетации растений по гумусовому слою было равномерным и в фазу кущения составляло в среднем 9,0 мг/кг. К фенологической фазе колошения содержание азота в почве снизилось на 37,8\%. Наиболее высокое расходование нитратного азота отмечено в фазу полной спелости - 54,2\%, что связано с выносом его яровой пшеницей. На распределение подвижного фосфора по фазам вегетации яровой пшеницы погодные условия не оказали заметного влияния. Максимальное содержание отмечалось в период кущения (11,3 мг/кг), затем происходило его снижение в фазу колошения и полной спелости (7,2 и 7,8 мг/кг) соответственно $\left(\mathrm{HCP}_{0,05}=0,3\right)$.

При ГТК $=1,4$ за период кущения суммарный запас влаги составил 222,4 мм. Учет запасов влаги в фазу колошения показал, что расход влаги из почвенного профиля со- ставлял 4,95\% в сравнении с предыдущей фазой. Заметного снижения уровня продуктивной влаги не отмечается вследствие частого выпадения атмосферных осадков, питавших почвенные горизонты. По результатам данных последнего периода вегетации наглядно видно действие растений на использование почвенной влаги. Наблюдается заметное расходование почвенной влаги 26,7\% (154,9 мм), что составляет относительно предыдущей фазы 56,5 мм.

Содержание нитратного азота в фазу кущения составляло всего 1,2 мг/кг. В фазу колошения отмечается увеличение нитратного азота на 77,2\%, и к моменту уборки расход нитратного азота в почве составляет более $70 \%$ от содержания в предыдущей фазе.

Изменение содержания подвижного фосфора по фазам вегетации во влажные годы $(\Gamma T К=1,4)$ проходило в сторону увеличения от кущения до полной спелости. Увеличение содержания фосфора за период вегетации яровой пшеницы составляет 97,7\%, что связано с увеличением температуры окружающей среды и лучшим прогреванием почвы.

Исследованиями подтверждено, что форма использования пашни оказала существенное влияние на содержание основных элементов питания (табл. 1).

По результатам наблюдений, растения на зернотравяном севообороте, из-за более высокого уровня плодородия почвы, всегда развиваются лучше, чем на зернопаровом севообороте, что сказывается на степени усвоения питательных элементов для формирования продуктивности.

Исследования показали, что по содержанию нитратного азота в среднем по горизонтам почвы наименьшее значение принадлежит целинному ценозу (1 мг/кг). В естественных ценозах преобладают формы аммонийного азота, что связано с действием температуры и условий увлажнения, которые более благоприятны для процесса аммонификации. Соотношение между нитратной и аммонийной формами азота в почве под пашней равнялось 4 , а под фитоценозами 0,48 (залежь) и 0,44 (целина). На обрабатываемых землях минимальное содержание нитратного азота отмечено на зернопаровом севообороте (3 мг/кг). Благодаря действию удобрений, содержание его увеличивается на 17,8\%. При включении в севооборот многолетних трав содержание азота увеличивается на $36,1 \%$, и на $43,8 \%$ на удобренном варианте. 
Таблица 1

Содержание питательных элементов в почве при различном ее использовании на разных дозах удобрений в среднем за период исследований в метровом слое, мг/кг

\begin{tabular}{|c|c|c|c|c|c|c|c|c|c|}
\hline \multirow{3}{*}{$\begin{array}{c}\text { Питательный } \\
\text { элемент, } \\
\text { мг/кг }\end{array}$} & \multirow{3}{*}{$\begin{array}{c}\text { Почвен- } \\
\text { ные гори- } \\
\text { зонты }\end{array}$} & \multicolumn{8}{|c|}{ Вид сельскохозяйственного использования почвы } \\
\hline & & \multicolumn{2}{|c|}{$\begin{array}{c}\text { Зернопаровой } \\
\text { севооборот }\end{array}$} & \multicolumn{2}{|c|}{$\begin{array}{c}\text { Зернотравяной } \\
\text { севооборот }\end{array}$} & \multicolumn{2}{|c|}{ Целина } & \multicolumn{2}{|c|}{ Залежь 35 лет } \\
\hline & & Б/y & $\mathrm{N}_{60}$ & Б/y & $\mathrm{N}_{60}$ & Б/y & $\mathrm{N}_{60}$ & Б/y & $\mathrm{N}_{60}$ \\
\hline \multirow{3}{*}{$\mathrm{N}-\mathrm{NO}_{3}$} & Гор. A & 4,7 & 6,7 & 4,7 & 7,5 & 1,6 & 2,4 & 0,8 & 1,5 \\
\hline & Гop. B & 2,1 & 2,2 & 3,2 & 4,8 & 0,7 & 1,2 & 2,4 & 2,7 \\
\hline & Гор. C & 2,0 & 2,0 & 5,1 & 5,6 & 0,5 & 0,7 & 3,9 & 3,9 \\
\hline $\begin{array}{l}\text { Среднее по } \\
\text { горизонтам } \\
\end{array}$ & $\mathrm{A}+\mathrm{B}+\mathrm{C}$ & 3,0 & 3,6 & 4,3 & 5,9 & 1,0 & 1,4 & 2,4 & 2,7 \\
\hline \multirow[t]{3}{*}{$\mathrm{P}_{2} \mathrm{O}_{5}$} & Гор. A & 10,8 & 11,1 & 19,5 & 23,9 & 18,3 & 20,1 & 44,0 & 45,8 \\
\hline & Гор. B & 1,3 & 2,3 & 3,1 & 4,1 & 2,3 & 2,7 & 19,2 & 22,1 \\
\hline & Гop. $\mathrm{C}$ & 2,1 & 0,8 & 2,3 & 1,4 & 1,9 & 2,1 & 11,2 & 14,6 \\
\hline $\begin{array}{l}\text { Среднее по } \\
\text { горизонтам }\end{array}$ & $\mathrm{A}+\mathrm{B}+\mathrm{C}$ & 4,7 & 4,7 & 8,3 & 9,8 & 7,5 & 8,3 & 24,8 & 27,5 \\
\hline \multicolumn{10}{|c|}{ Статистическая обработка по N-NO } \\
\hline \multicolumn{2}{|c|}{ Факторы } & \multicolumn{3}{|c|}{$\mathrm{HCP}_{0}{ }^{\prime} 05$} & \multicolumn{3}{|c|}{ Fтеор. } & \multicolumn{2}{|c|}{ Fфакт. } \\
\hline \multicolumn{2}{|c|}{ А (угодье) } & \multicolumn{3}{|c|}{0,4} & \multicolumn{3}{|c|}{3,0} & \multicolumn{2}{|c|}{$160,3^{*}$} \\
\hline \multicolumn{2}{|c|}{ В (горизонты) } & \multicolumn{3}{|c|}{0,3} & \multicolumn{3}{|c|}{3,4} & \multicolumn{2}{|c|}{$28,8^{*}$} \\
\hline \multicolumn{2}{|c|}{ С (удобрение) } & \multicolumn{3}{|c|}{0,3} & \multicolumn{3}{|c|}{4,3} & \multicolumn{2}{|c|}{$7,6^{*}$} \\
\hline \multicolumn{10}{|c|}{ Статистическая обработка по $\mathrm{P}_{2} \mathrm{O}_{5}$} \\
\hline \multicolumn{2}{|c|}{ Факторы } & \multicolumn{3}{|c|}{$\mathrm{HCP}_{005}$} & \multicolumn{3}{|c|}{ Fтеор. } & \multicolumn{2}{|c|}{ Fфакт. } \\
\hline \multicolumn{2}{|c|}{ А (угодье) } & \multicolumn{3}{|c|}{0,4} & \multicolumn{3}{|c|}{3,0} & 480 & \\
\hline В (гориз & онты) & & 0,3 & & & 3,4 & & 165 & \\
\hline C (удоб) & ение) & & 0,3 & & & 4,3 & & & \\
\hline
\end{tabular}

Продуктивность агробиоценозов, т з.ед/га

Таблица 2

\begin{tabular}{|c|c|c|c|c|c|c|c|c|c|}
\hline \multirow[t]{3}{*}{ ГТК } & \multicolumn{9}{|c|}{ Угодья } \\
\hline & \multicolumn{3}{|c|}{ Целина } & \multicolumn{3}{|c|}{ Залежь 35 лет } & \multicolumn{3}{|c|}{$\begin{array}{l}\text { Пашня (яр. пшеница в сред- } \\
\text { нем по двум севооборотам) }\end{array}$} \\
\hline & Б/y & $\mathrm{N}_{30}$ & $\mathrm{~N}_{60}$ & $\mathrm{~b} / \mathrm{y}$ & $\mathrm{N}_{30}$ & $\mathrm{~N}_{60}$ & $\mathrm{~b} / \mathrm{y}$ & $\mathrm{N}_{30}$ & $\mathrm{~N}_{60}$ \\
\hline 0,4 & 0,31 & 0,35 & 0,56 & 1,00 & 1,48 & 1,84 & 0,80 & 0,85 & 1,09 \\
\hline 1,1 & 1,19 & 1,77 & 2,38 & 1,33 & 2,12 & 2,71 & 1,55 & 2,03 & 2,65 \\
\hline 1,4 & 2,10 & 2,15 & 2,70 & 3,05 & 3,45 & 3,55 & 1,94 & 2,75 & 2,95 \\
\hline $\begin{array}{l}\text { Среднее } \\
\text { значение }\end{array}$ & 1,20 & 1,42 & 1,88 & 1,79 & 2,35 & 2,70 & 1,43 & 1,88 & 2,23 \\
\hline \multicolumn{10}{|c|}{ Статистическая обработка данных } \\
\hline \multicolumn{2}{|c|}{ Факторы } & \multicolumn{4}{|c|}{$\mathrm{HCP}_{0,05}$} & \multicolumn{2}{|l|}{ Fтеор. } & \multicolumn{2}{|c|}{ Fфакт. } \\
\hline \multicolumn{2}{|c|}{ А (агробиоценоз) } & \multicolumn{4}{|c|}{0,23} & \multicolumn{2}{|l|}{3,18} & \multicolumn{2}{|c|}{$128,75^{*}$} \\
\hline \multicolumn{2}{|c|}{ В (удобрение) } & \multicolumn{4}{|c|}{0,23} & \multicolumn{2}{|l|}{3,18} & \multicolumn{2}{|c|}{$23,62 *$} \\
\hline \multicolumn{2}{|c|}{ C (годы) } & \multicolumn{4}{|c|}{0,23} & 3,18 & & \multicolumn{2}{|c|}{$24,38^{*}$} \\
\hline
\end{tabular}

На залежных землях содержание нитратного азота в среднем по профилю на $35 \%$ меньше, чем на зернопаровом, и на $51 \%$ меньше, чем на зернотравяном севооборотах. Целинные земли оказались еще менее обогащены нитратным азотом, чем залежные.

В среднем в метровом слое почвы содержание доступного фосфора под залежью было в 3,5 раза выше, чем под остальными видами использования пашни. Наименьшее содержание отмечено в почвах зернопарового севооборота. На удобренном варианте зернотравяного севооборота отмечается увеличение подвижного фосфора на 15,7 \%, что является наибольшим значением на двух севооборотах. 
Под исследуемые фитоценозы для интенсификации процессов почвообразования вносились 2 дозы азотного удобрения (аммиачная селитра) из расчета: 30 и 60 кг/га (табл. 2).

На целине и залежи удобрения вносились в период отрастания трав, а под яровую пшеницу - под предпосевную культивацию.

Максимальное эффективное действие азотных удобрений отмечалось на необрабатываемых фонах в годы с ГТК $=0,4$ и 1,1. Внесение $\mathrm{N}_{30}$ по сравнению с неудобренным вариантом позволило увеличить урожайность залежного ценоза на $48 \%$ при ГТК $=0,4$ и на $59,4 \%$ при ГТК = 1,1, а целинного ценоза на $12,9 \%$ и 48,7\% соответственно. На пашне в эти годы уровень продуктивности, на варианте с внесением 30 кг д.в. аммиачной селитры, значительно уступал другим изучаемым угодьям. По сравнению с неудобренным контролем эффективность доз вносимых удобрений составила $6,25 \%$ и $31 \%$.

Во влажный год $(\Gamma T K=1,4)$ действие $\mathrm{N}_{30}$ увеличило продуктивность пашни на 41,8\%, залежи на 16,4\% и целины на 28,6\%.

По сравнению с $\mathrm{N}_{30}$ внесение двойной дозы азотного удобрения $\left(\mathrm{N}_{60}\right)$, в среднем по всем сельскохозяйственным фонам и годам, способствовало росту продуктивности на $116 \%$. Наиболее эффективно двойная доза работала под залежью 35 лет. Прибавка продуктивности от двойной дозы по сравнению с одинарной составила в сухой год $-84 \%$, в увлажненный - 103,8\%. В условиях хорошего увлажнения $(\Gamma \mathrm{TK}=1,4)$ максимальный эффект от использования удобрений дает обрабатываемая пашня, в то время как при засушливых условиях $(\Gamma \mathrm{TK}=0,4-1,1)$ наибольшую прибавку дают фитоценозы, за счет созданного микроклимата, где почвенный профиль не пересыхает, а плотный растительный слой не дает почвенной влаге испаряться.

\section{Выводы}

Исследованиями подтверждено, что вид использования почвы в агроландшафте оказал существенное влияние на содержание основных элементов питания. На залежных землях содержание нитратного азота в среднем по профилю на $35 \%$ меньше, чем на зернопаровом, и на 51 \% меньше, чем на зернотравяном севооборотах. Целинные земли оказались еще менее обогащены нитратным азотом, чем залежные. Снижение содержания азота на ненарушенных механическими обработками почвах связано с агрофизическими свойствами почвы и высоким уровнем дифференциации размещения органических остатков по гумусовому профилю почвы.
Установлена зависимость уровня продуктивности от способа использования почвы, условий произрастания и влияния удобрений. По всем годам исследований залежные ценозы отличались высокой продуктивностью (2,28 т з.ед/га), целинные - минимальной (1,5 т з.ед/га). Пашня занимала промежуточное положение между соответствующими показателями целины и залежи (1,85 т з.ед/га).

Максимальное эффективное действие по двум дозам $\left(\mathrm{N}_{30}\right.$ и $\left.\mathrm{N}_{60}\right)$ азотных удобрений отмечалось на необрабатываемых фонах при ГТК $=0,4-1,1 . \quad$ Прибавка продуктивности для залежи составила 53,7\% $\left(\mathrm{N}_{30}\right)$ и 92\% $\left(\mathrm{N}_{60}\right)$, для целины $30,8 \%\left(\mathrm{~N}_{30}\right)$ и $72,3 \%\left(\mathrm{~N}_{60}\right)$, Однако при ГТК $=1,4$ большая отзывчивость на вносимые удобрения оказалась на пашне $41,8 \%\left(\mathrm{~N}_{30}\right)$ и $52,1 \%\left(\mathrm{~N}_{60}\right)$.

\section{Список литературы}

1. Влияние почвенно-агрохимических показателей на формирование корневой системы яровой мягкой пшеницы (triticum aestivum L.) в различных погодных условиях на черноземах южных / И.Ф. Медведев [и др.] // Проблемы агрохимии и экологии. - 2014. - № 3. - С. 8-13.

2. Каземиров С.В. Экологические аспекты развития почвенно-растительной системы южного чернозема на залежах: автореф. дис. ... канд. с.-х. наук. - Саратов, 2007. - 20 с.

3. Левицкая Н.Г. Засухи в Поволжье и их влияние на производство зерна / Н.Г. Левицкая, О.В. Шаталова, Г.Ф. Иванова // Аграрный вестник Юго-Востока. - 2010. № 3-4(6-7). - С. 71-74.

4. Прянишников А.И. Изменение экологических условий формирования продуктивности пшеницы в Поволжье / А.И. Прянишников, Н.Г. Левицкая, И.И. Демакина // Зернобобовые и крупяные культуры. - 2017. - № 3. - С. 58-63.

5. Оптимизация доз азотных и фосфорных удобрений на черноземных почвах Поволжья с различным содержанием фосфор а/ М.П. Чуб [и др.] // Плодородие. - 2017. - № 2. - С. 8-11.

\section{References}

1. Medvedev I.F., Dereviagin S.S., Gubarev D.I., Buzueva A.S., Azarov K.A. Effect of soilagrochemical parameters on the formation of root system of spring wheat (Triticum aestivum L.) in different weather conditions on the southern chernozems [Vliianie pochvenno-agrokhimicheskikh pokazatelei na formirovanie kornevoi sistemy iarovoi miagkoi pshenitsy (triticum aestivum L.) v razlichnykh pogodnykh usloviiakh na chernozemakh iuzhnykh]. Problemy agrokhimii i ekologii Problems of agrochemistry and ecology, 2014, no. 3, pp. 8-13.

2. Kazemirov S.V. Ekologicheskie aspekty razvitiia pochvenno-rastitel'noi sistemy iuzhnogo chernozema na zalezhakh [Ecological aspects of the development of the soilplant system of southern chernozem on deposits]. Saratov, FGOU VPO Saratovskii GAU im. N.I. Vavilova, 2007, 20

3. Levitskaia N.G., Shatalova O.V., Ivanova G.F. Droughts in the Volga Region and Their Influence to Grain Production [Zasukhi v Povolzh'e i ikh vliianie na proizvodstvo zerna]. Agrarnyi vestnik Iugo-Vostoka - Agrarian Reporter of SouthEast, 2010, vol. 4, no. 3, pp. 71-74.

4. Prianishnikov A.I., Levitskaia N.G., Demakina I.I. The change in the environmental conditions of formation of productivity of wheat in the volga region [Izmenenie ekologicheskikh uslovii formirovaniia produktivnosti pshenitsy v Povolzh'e]. Zernobobovye i krupianye kul'tury - grained and crop crops, 2017, no. 3, pp. 58-63.

5. Chub M.P., Pron'ko V.V., Iaroshenko T.M., Klimova N.F., Zhuravlev D.Iu. Optimization of Nitrogen and Phosphorus Fertilizer Application Rates on Chernozemic Soils with Different Phosphorus Contents in the Volga Region [Optimizatsiia doz azotnykh i fosfornykh udobrenii na chernozemnykh pochvakh Povolzh'ia s razlichnym soderzhaniem fosfora]. Plodorodie - Plodorodie, 2017, no. 2, pp. 8-11. 